Pacific Journal of Mathematics

LINEAR TRANSFORMATIONS OF TENSOR PRODUCTS 


\title{
LINEAR TRANSFORMATIONS OF TENSOR PRODUCTS PRESERVING A FIXED RANK
}

\author{
D. Ž. DJoković
}

\begin{abstract}
In this paper $T$ is a linear transformation from a tensor product $X \otimes Y$ into $U \otimes V$, where $X, Y, U, V$ are vector spaces over an infinite field $F$. The main result gives a characterization of surjective transformations $T$ for which there is a positive integer $k(k<\operatorname{dim} U, k<\operatorname{dim} V)$ such that whenever $z \in X \otimes Y$ has rank $k$ then also $T z \in U \otimes V$ has rank $k$. It is shown that $T=A \otimes B$ or $T=S \circ(C \otimes D)$ where $A, B, C, D$ are appropriate linear isomorphisms and $S$ is the canonical isomorphism of $V \otimes U$ onto $U \otimes V$.
\end{abstract}

Let $F$ be an infinite field and $X, Y, U, V$ vector spaces over $F$. We denote by $T$ a linear transformation of the tensor product $X \otimes Y$ into $U \otimes V$. The rank of a tensor $z \in X \otimes Y$ is denoted by $\rho(z)$. By definition $\rho(o)=0$. The subspace of $X$ spaned by the vectors $x_{1}, \cdots, x_{n} \in X$ will be denoted by $\left\langle x_{1}, \cdots, x_{n}\right\rangle$.

Lemma 1. Let $k$ be a positive integer such that $z \in X \otimes Y$ and $\rho(z)=k$ imply that $\rho(T z)=k$. Then $\rho(z) \leqq k$ implies that $\rho(T z) \leqq k$ for all $z$.

Proof. If this is not true then for some $z \in X \otimes Y, z \neq 0$, we have $\rho(z)<k$ and $\rho(T z)>k$. There exists $t \in X \otimes Y$ such that $\rho(t)+\rho(z)=k$ and moreover $\rho(z+\lambda t)=k$ for all $\lambda \neq 0, \lambda \in F$. Let

$$
T z: \quad \sum_{i=1}^{m} u_{i} \otimes v_{i}, \quad m=\rho(T z) .
$$

Since $u_{i} \in U$ are linearly independent and also $v_{i} \in V$ we can consider them as contained in a basis of $U$ and $V$, respectively. The matrix of coordinates of $T z$ has the form

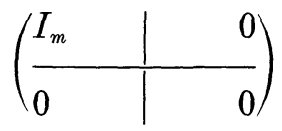

where $I_{m}$ is the identity $m \times m$ matrix. Let

$$
\left(\begin{array}{l|l}
A_{m} & B \\
\hline C & D
\end{array}\right)
$$

be the matrix of coordinates of $T t$. Then the "minor $\left|I_{m}+\lambda A_{m}\right|$ of the matrix of $T(z+\lambda t)$ has the form 


$$
1+\alpha_{1} \lambda+\alpha_{2} \lambda^{2}+\cdots
$$

Since $F$ is infinite we can choose $\lambda \neq 0$ so that $\left|I_{m}+\lambda A_{m}\right| \neq 0$. For this value of $\lambda$ we have

$$
\rho(z+\lambda t)=k, \quad \rho(T(z+\lambda t)) \geqq m>k
$$

which contradicts our assumption. This proves the lemma.

LemMA 2. Let $k$ be a positive integer such that $z \in X \otimes Y$ and $\rho(z) \leqq k i m p l y \rho(T z) \leqq k$. If $T$ is surjective and $k<\operatorname{dim} U, k<\operatorname{dim} V$ then $\rho(z) \geqq \rho(T z)$ for all $z$.

Proof. Assume that for some $z$ we have $\rho(z)<\rho(T z)$. Clearly, we can assume in addition that $\rho(z)=1$. Therefore $k>1$. By assumption $\rho(z) \leqq k$ implies that $\rho(T z) \leqq k$. Let $s \leqq k$ be the maximal integer such that there exists $z \in X \otimes Y$ satisfying $\rho(z)<s$ and $\rho(T z)=s$. Let

$$
T z=\sum_{i=1}^{s} u_{i} \otimes v_{i} .
$$

We can choose $u_{s+1} \in U, v_{s+1} \in V$ such that $u_{s+1} \notin\left\langle u_{1}, \cdots, u_{s}\right\rangle$ and $v_{s+1} \notin\left\langle v_{1}, \cdots, v_{s}\right\rangle$. Since $u_{i} \in U$ are linearly independent and $v_{i} \in V$ also linearly independent we can assume that these vectors are contained in a basis of $U$ and $V$, respectively. Since $T$ is surjective there exists $t \in X \otimes Y$ such that $\rho(t)=1$ and the $(s+1, s+1)$-coordinate $a_{s+1, s+1}$ of $T t$ is nonzero. The minor of order $s+1$ in the upper left corner of the matrix of $T(z+\lambda t)$ has the form

$$
a_{s+1, s+1} \lambda+\alpha_{2} \lambda^{2}+\cdots
$$

Since $a_{s+1, s+1} \neq 0$ we can choose $\lambda \neq 0$ so that the minor is nonzero. For this value of $\lambda$ we have

$$
\begin{gathered}
\rho(z+\lambda t) \leqq \rho(z)+1 \leqq s \leqq k, \\
\rho(T(z+\lambda t)) \geqq s+1 .
\end{gathered}
$$

If $s=k$ this contradicts our assumption. If $s<k$ this contradicts the maximality of $s$. Hence, Lemma 2 is proved.

Lemma 3. Let $k$ be a positive integer such that $z \in X \otimes Y$ and $\rho(z)=k$ imply that $\rho(T z)=k$. If $T$ is surjective and $k<\operatorname{dim} U$, $k<\operatorname{dim} V$ then $\rho(z)=\rho(T z)$ for each $z \in X \otimes Y$ satisfying $\rho(z) \leqq k$.

Proof. The assertion is trivial if $\rho(z)=0$ or $k$. Let $0<\rho(z)<k$. Choose $t \in X \otimes Y$ such that 


$$
\rho(z+t)=\rho(z)+\rho(t)=k
$$

Using this and Lemmas 1 and 2 we deduce

$$
\begin{aligned}
& \rho(T(z+t))=\rho(T z+T t)=k, \\
& \rho(T z)+\rho(T t) \geqq k, \\
& \rho(T z)+\rho(t) \geqq k, \\
& \rho(T z) \geqq \rho(z) .
\end{aligned}
$$

Since by Lemma $2, \rho(T z) \leqq \rho(z)$ we are ready.

The following Theorem is an immediate consequence of Lemma 3 and Theorem 3.4 of [3]:

THEOREM 1. Let $k$ be a positive integer such that $z \in X \otimes Y$ and $\rho(z)=k$ imply that $\rho(T z)=k$. If $T$ is surjective and $k<\operatorname{dim} U$, $k<\operatorname{dim} V$ then

$$
T=A \otimes B
$$

or

$$
T=S \circ(C \otimes D)
$$

where

$$
\begin{array}{ll}
A: X \rightarrow U, & B: Y \rightarrow V, \\
C: X \rightarrow V, & D: Y \rightarrow U,
\end{array}
$$

are bijective linear transformations and $S$ is the canonical isomorphism of $V \otimes U$ onto $U \otimes V$.

This theorem gives a partial answer to a conjecture of Marcus and Moyls [2].

From Lemma 2 and Theorem 3.4 of [3] we get the following variant:

THEOREM 2. Let $k$ be a positive integer such that $z \in X \otimes Y$ and $\rho(z) \leqq k$ imply that $\rho(T z) \leqq k$. If $T$ is bijective and $k<\operatorname{dim} U$, $k<\operatorname{dim} V$ then (1) or (2) holds.

When $X=Y=U=V, \operatorname{dim} X=n, k=n-1$ we get a result of Dieudonné [1].

\section{REFERENCES}

1. J. Dieudonné, Sur une généralisation du groupe orthogonale à quatre variables, Archiv der Math. 1 (1948), 282-287. 
2. M. Marcus and B. N. Moyls, Transformations on tensor product spaces, Pacific J. Math. 9 (1959), 1215-1221.

3. R. Westwick, Transformations on tensor spaces, Pacific J. Math. 23 (1967), 613-620.

Received August 21, 1968. This work was supported in part by N. R. C. Grant A-5285.

UNIVERSITY OF WATERLOO 


\title{
PACIFIC JOURNAL OF MATHEMATICS
}

\author{
EDITORS
}

H. ROYDEN

Stanford University

Stanford, California

R. R. PhelPS

University of Washington

Seattle, Washington 98105
J. DUGUNDJI

Department of Mathematics

University of Southern California

Los Angeles, California 90007

RICHARD ARENS

University of California

Los Angeles, California 90024

\section{ASSOCIATE EDITORS}
E. F. BECKENBACH
B. H. NeumanN
F. WOLF
K. YoSHIDA

\section{SUPPORTING INSTITUTIONS}

\author{
UNIVERSITY OF BRITISH COLUMBIA \\ CALIFORNIA INSTITUTE OF TECHNOLOGY \\ UNIVERSITY OF CALIFORNIA \\ MONTANA STATE UNIVERSITY \\ UNIVERSITY OF NEVADA \\ NEW MEXICO STATE UNIVERSITY \\ OREGON STATE UNIVERSITY \\ UNIVERSITY OF OREGON \\ OSAKA UNIVERSITY \\ UNIVERSITY OF SOUTHERN CALIFORNIA
}

\author{
STANFORD UNIVERSITY \\ UNIVERSITY OF TOKYO \\ UNIVERSITY OF UTAH \\ WASHINGTON STATE UNIVERSITY \\ UNIVERSITY OF WASHINGTON \\ $\stackrel{*}{*} \stackrel{*}{*}{ }^{*}{ }^{*}$ \\ CHEVRON RESEARCH CORPORATION \\ TRW SYSTEMS \\ NAVAL WEAPONS CENTER
}

The Supporting Institutions listed above contribute to the cost of publication of this Journal, but they are not owners or publishers and have no responsibility for its content or policies.

Mathematical papers intended for publication in the Pacific Journal of Mathematics should be in typed form or offset-reproduced, double spaced with large margins. Underline Greek letters in red, German in green, and script in blue. The first paragraph or two must be capable of being used separately as a synopsis of the entire paper. It should not contain references to the bibliography. Manuscripts, in duplicate if possible, may be sent to any one of the four editors. Please classify according to the scheme of Math. Rev. 36, 1539-1546. All other communications to the editors should be addressed to the managing editor, Richard Arens, University of California, Los Angeles, California, 90024.

50 reprints are provided free for each article; additional copies may be obtained at cost in multiples of 50 .

The Pacific Journal of Mathematics is published monthly. Effective with Volume 16 the price per volume (3 numbers) is $\$ 8.00$; single issues, $\$ 3.00$. Special price for current issues to individual faculty members of supporting institutions and to individual members of the American Mathematical Society: $\$ 4.00$ per volume; single issues $\$ 1.50$. Back numbers are available.

Subscriptions, orders for back numbers, and changes of address should be sent to Pacific Journal of Mathematics, 103 Highland Boulevard, Berkeley, California, 94708.

PUBLISHED BY PACIFIC JOURNAL OF MATHEMATICS, A NON-PROFIT CORPORATION

Printed at Kokusai Bunken Insatsusha (International Academic Printing Co., Ltd.), 7-17, Fujimi 2-chome, Chiyoda-ku, Tokyo, Japan. 


\section{Pacific Journal of Mathematics \\ Vol. 30, No. $2 \quad$ October, 1969}

Gregory Frank Bachelis, Homomorphisms of annihilator Banach algebras.

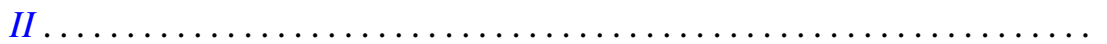

Leon Bernstein and Helmut Hasse, An explicit formula for the units of an algebraic number field of degree $n \geq 2 \ldots \ldots \ldots \ldots \ldots \ldots \ldots . \ldots 29$

David W. Boyd, Best constants in a class of integral inequalities ........ 367

Paul F. Conrad and John Dauns, An embedding theorem for lattice-ordered

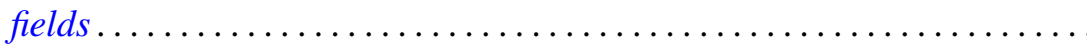

H. P. Dikshit, Summability of Fourier series by triangular matrix

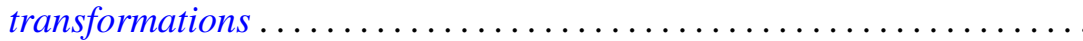

Dragomir Z. Djokovic, Linear transformations of tensor products preserving a fixed rank............................. 411

John J. F. Fournier, Extensions of a Fourier multiplier theorem of Paley . . . 415 Robert Paul Kopp, A subcollection of algebras in a collection of Banach

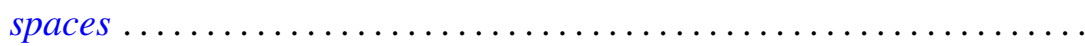

Lawrence Louis Larmore, Twisted cohomology and enumeration of vector bundles ...................................... 437

William Grenfell Leavitt and Yu-Lee Lee, A radical coinciding with the lower radical in associative and alternative rings .................

Samuel Merrill and Nand Lal, Characterization of certain invariant subspaces of $H^{p}$ and $L^{p}$ spaces derived from logmodular

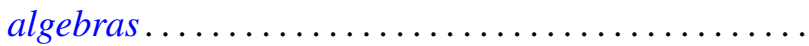

Sam Bernard Nadler, Jr., Multi-valued contraction mappings ....

T. V. Panchapagesan, Semi-groups of scalar type operators in Banach spaces ....................................

J. W. Spellmann, Concerning the infinite differentiability of semigroup motions

H. M. (Hari Mohan) Srivastava, A note on certain dual series equations involving Laguerre polynomials.

Ernest Lester Stitzinger, A nonimbedding theorem of associative algebras................................

J. Jerry Uhl, Jr., Martingales of vector valued set functions ...

John Mays Worrell Jr., On continuous mappings of metacompact $\check{C} e c h$

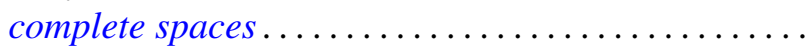

